\title{
Ecological models based on people's knowledge: a multi-step fuzzy cognitive mapping approach
}

\author{
Uygar Özesmi*, Stacy L. Özesmi \\ Environmental Science Chair, Department of Environmental Engineering, Erciyes University, Kayseri 38039, Turkey
}

Received 2 October 2002; received in revised form 14 October 2003; accepted 31 October 2003

\begin{abstract}
Many types of ecological or environmental problems would benefit from models based on people's knowledge. To create ecological models with both expert and local people's knowledge, a multi-step fuzzy cognitive mapping approach is proposed. A cognitive map can be made of almost any system or problem. Cognitive maps are qualitative models of a system, consisting of variables and the causal relationships between those variables. We describe how our cognitive mapping research has been used in real environmental management applications. This research includes examining the perceptions of different stakeholders in an environmental conflict, obtaining the perceptions of different stakeholders to facilitate the development of participatory environmental management plans, and determining the wants and desires for resettlement of people displaced by a large scale dam project. Based on our research, which involved six separate studies, we have found that interviewees complete their cognitive maps in 40-90 min on average. These maps contain an average of $23 \pm 2$ S.D. variables with $37 \pm 3$ S.D. connections. People generally put more forcing functions into their maps than utility variables. Fuzzy cognitive mapping offers many advantages for ecological modeling including the ability to include abstract and aggregate variables in models, the ability to model relationships which are not known with certainty, the ability to model complex relationships which are full of feedback loops, and the ease and speed of obtaining and combining different knowledge sources and of running different policy options.
\end{abstract}

(C) 2003 Elsevier B.V. All rights reserved.

Keywords: Cognitive map; Fuzzy cognitive mapping; Cognitive models; Graph theory; Artificial intelligence; Expert systems; Local knowledge systems

\section{Introduction}

Modeling ecological or environmental problems is a challenge when humans are involved. We identified four types of problems where gaining insights or predicting system behavior can be very difficult. The first type involves human behavior and how human actions can affect an ecosystem. Examples include management of sport or commercial fisheries, where anglers

\footnotetext{
* Corresponding author. Tel.: +90-352-437-6748; fax: +90-352-437-6748.

E-mail address: uozesmi@erciyes.edu.tr (U. Özesmi).
}

and fishing effort can have a considerable effect on the ecosystem. The behavior of commercial fisherman and anglers needs to be accounted for in these models because knowledge of fishing effort in response to regulations is needed to choose appropriate management options (Dreyfus-Leon and Kleiber, 2001; Radomski and Goeman, 1996). In such cases a modeling tool to determine perceptions of fishermen concerning a fishery and their probable actions given different management scenarios would be useful.

The second type of problem involves instances where detailed scientific data are lacking but local knowledge of people adapted to an ecosystem is 
available. Much could be learned from incorporating this local or indigenous knowledge but typically models have no means to do this.

The third type is "wicked" environmental problems (Mason and Mitroff, 1981). These problems are complex, involve many parties, and have no easy solutions or right answers. However, decisions must be made. A useful modeling tool for analyzing such problems would bring together the knowledge of many different experts from different disciplines, be able to compare their perceptions and to simulate different policy options, allowing for discussion and insight into the advantages and disadvantages of possible decisions.

Finally the fourth type of problem concerns ecosystem management where public involvement is desired or even mandated by law. Most ecosystem models typically address things such as primary production while the public is concerned with properties such as human health or costs of different management options (Hobbs et al., 2002). In these cases the modeling method should be able to incorporate public opinions about these higher-level variables of concern to the public. In addition, the model could be used to inform the public regarding different management options, and enable public support for management decisions.

All of these types of problems would benefit from models based on people's knowledge. Cognitive mapping provides a means to do this. Özesmi (1999a) developed a multi-step fuzzy cognitive mapping approach for analyzing how people perceive an ecosystem, and for comparing and contrasting the perceptions of different people or groups of stakeholders. The multi-step approach is a synthesis of relevant useful techniques from many disparate disciplines on cognitive mapping. This article describes this multi-step approach in detail, providing a methodological tutorial and some examples from our own research. In addition, to our knowledge this article is the first review of cognitive mapping for ecological modeling and environmental management. First we give a brief introduction to cognitive mapping including its history and some examples of its uses. We compare FCM to some other techniques and discuss the advantages and disadvantages of cognitive mapping. Based on our research and examples from the literature we propose that some generalities about the structure of cognitive maps can be made. As this article is a synthesis of a large body of knowledge from different fields on cognitive mapping, there are many new technical terms. For the reader's convenience, the first time a new term is used, it is explained and a reference to the relevant literature is given.

\subsection{Introduction to cognitive mapping}

What is a cognitive map? A cognitive map can be described as a qualitative model of how a given system operates. The map is based on defined variables and the causal relationships between these variables. These variables can be physical quantities that can be measured, such as amount of precipitation or percent vegetation cover, or complex aggregate and abstract ideas, such as political forces or aesthetics. The person making the cognitive map decides what the important variables are which affect a system and then draws causal relationships among these variables indicating the relative strength of the relationships with a number between -1 and 1 . The directions of the causal relationships are indicated with arrowheads. Cognitive maps are especially applicable and useful tools for modeling complex relationships among variables. With cognitive mapping the decision-makers' maps can be examined, compared as to their similarities and differences, and discussed. In addition the effects of different policy options can easily be modeled. Maps can also be made with local people, who often have quite a detailed understanding of the ecosystem (Özesmi, 1999a,b). Their input can be important for decision-making and for the public to accept the chosen solutions.

\subsection{History of cognitive mapping}

Cognitive maps are directed graphs, or digraphs, and thus they have their historical origins in graph theory, which started with Euler in 1736 (Biggs et al., 1976). In digraphs each link (line or connection) between variables (points or nodes) has a direction (Harary et al., 1965). Anthropologists have used signed digraphs to represent different social structures in human society (Hage and Harary, 1983). In ecology, Puccia (1983) used a signed digraph model for studying the relationships among benthic organisms. Axelrod (1976) was the first to use digraphs to show causal relationships among variables as defined and described by people, rather than by the researcher. 
He called these digraphs cognitive maps (term first used by Tolman, 1948). Many studies have used cognitive mapping to look at decision-making as well as to examine people's perceptions of complex social systems (Axelrod, 1976; Bauer, 1975; Bougon et al., 1977; Brown, 1992; Carley and Palmquist, 1992; Cossette and Audet, 1992; Hart, 1977; Klein and Cooper, 1982; Malone, 1975; Montazemi and Conrath, 1986; Nakamura et al., 1982; Rappaport, 1979; Roberts, 1973).

Kosko (1986) modified Axelrod's cognitive maps, which were binary, by applying fuzzy causal functions with real numbers in $[-1,1]$ to the connections, thus the term fuzzy cognitive map (FCM). Kosko was also the first to compute the outcome of a FCM, or the FCM inference, as well as to model the effect of different policy options using a neural network computational method (Kosko, 1987).

FCM has been used to model a variety of things in different fields: the physiology of appetite (Taber and Siegel, 1987), political developments (Taber, 1991), electrical circuits (Styblinski and Meyer, 1988), a virtual world of dolphins, shark, and fish (Dickerson and Kosko, 1994), organizational behavior and job satisfaction (Craiger et al., 1996), and economic/demographics of world nations (Schneider et al., 1998). Recent applications have included using expert knowledge to create FCMs that are combined with data mining of the world wide web (Hong and Han, 2002; Lee et al., 2002).

In ecology, the use of FCMs has been limited. Radomski and Goeman (1996) used FCM to suggest ways to improve decision-making in sport-fisheries management by sending questionnaires to experts asking them the important variables and the relationships between these variables. Although they emphasized the importance of knowledge concerning angler behavior when making management decisions, they did not incorporate the opinions of anglers in their model. Hobbs et al. (2002) used FCM to define management objectives for the Lake Erie ecosystem. Their FCM modeling process involved the participation of many experts and some members of the public, allowing for discussion and insight into the potential effects of different management actions. Özesmi (1999a,b) first used FCM to analyze the perceptions about an ecosystem held by people in different stakeholder groups. Özesmi and Özesmi (2003) used FCM to an- alyze the perceptions of different stakeholder groups about a lake ecosystem in order to create a participatory management plan. Dadaser and Özesmi (2001, 2002) used FCM to obtain the perceptions of different stakeholder groups in two wetland ecosystems in central Turkey. Recently applications of cognitive mapping have appeared in forest management. Skov and Svenning (2003) combined FCM with a GIS to use expert knowledge to predict plant habitat suitability in a forest. Hjorts $\varnothing$ (2004) discussed the use of a cognitive mapping approach called strategic option development and analysis (SODA) to increase stakeholder participation in forest management in Denmark. Mendoza and Prabhu (2003) used cognitive mapping to examine the linkages and interactions between indicators obtained from a multi-criteria approach to sustainable forest management.

\subsection{Comparison to other methods}

In this section we compare FCMs to other methods in ecological modeling and environmental management.

The use of expert systems is increasing in ecological modeling (i.e. Yamada et al., 2003). Expert systems require the construction of a knowledge base which is taken from the experts' experience. Compared to most of these methods, FCMs are relatively quicker and easier to acquire from the knowledge sources, who do not usually think in equations. With FCMs you can have as many knowledge sources as wanted with diverse knowledge and different degrees of expertise. These knowledge sources can all be easily combined into one FCM. There is no restriction on the number of experts or on the number of concepts.

Structural equation modeling (SEM) (also known as causal modeling, covariance structural modeling, LISREL and others) is based on the statistical model developed by Jöreskog (1977). Causal relationships among the variables in the models are specified and tested with parameter estimation procedures, usually maximum likelihood. Structural equation modeling techniques are typically used to confirm or disprove an a priori hypothesized model. However, they can also be used as an exploratory modeling tool. Currently ecological applications of SEM are increasing (Iriondo et al., 2003; Shipley, 2000). Craiger et al. (1996) compared SEM with FCM. The limitations 
of SEM include nonconvergence of solutions and the inability to estimate parameters if the model and data are insufficient (under identification). In contrast FCMs are not concerned with parameter estimation but instead give qualitative information. Because of this FCMs facilitate pattern prediction, or changes in the behavior of the model. The person making the map decides on the strengths, these strengths can be changed easily and more simulations done to learn how the model changes with changing strengths of relationships. SEM often has the problem of model underidentification, especially with complex systems. In addition feedback loops must be removed from the model. However, FCMs can have unlimited complexity, including an unlimited number of concepts and reciprocal causal (feedback) relationships.

Multiattribute decision theory has been widely used in ranking a finite number of alternatives characterized by multiple, conflicting criteria or attributes (i.e. Luria and Aspinall, 2003). It allows for the measurement and aggregation of the performance of one or more options with respect to a variety of both qualitative and quantitative factors (criteria) into a single value. With multiattribute decision theory the alternatives need to be chosen and the factors and their weights. In contrast, with FCM the technique can be used to suggest the alternatives based on stakeholder input where each person making an FCM thinks of what is important and what should be included. In addition, FCM allows feedback loops.

Systems dynamics models use differential or difference equations to describe a system's response to external factors (i.e. Håkanson and Boulion, 2003). They are used to model long term dynamic behavior of ecosystems. In contrast FCMs are not dynamic models. Systems dynamics models require a lot of empirical data about the ecosystem. FCMs are more appropriate for data poor situations. Although Stave (2003) used a systems dynamics model to engage stakeholder interest and build stakeholder understanding of the system and the basis for management decisions concerning water supply in Las Vegas, NV, USA, our multi-step FCM method is a participatory approach where stakeholders themselves are involved in building the model.

Interestingly studies of Uluabat Lake in Turkey have been done with both the multi-step FCM approach (Özesmi and Özesmi, 2003) and a systems dynamics model (Güneralp and Barlas, 2003). For the systems dynamics model, the authors admit that some of the data needed is either unreliable or not available and results need to be interpreted in that light. Although many simplifying assumptions are made, the systems dynamics model also includes social and economic components in addition to ecological, unlike most systems dynamics models. Based on the systems dynamics model the effect of different policy options was simulated. The authors concluded that the model is to be a laboratory where the effect of different policy options can be simulated and suggested ways in which the model could be improved. The systems dynamics model predicted that the lake ecosystem would not go to a turbid water state with few macrophytes. However, as of 2003, macrophytes have declined, especially submerged macrophytes. Although algae is not abundant, the water is turbid from suspended solids. The FCM model predicts that lake pollution continues to increase. The FCM was based on the perceptions of many stakeholders concerning the ecosystem. But the main difference in the modeling approaches is the purpose of the models. The FCM was used to develop a participatory management plan with the goals and objectives based on the stakeholders' FCMs. Because the management plan was based on stakeholder input the stakeholders were able to take ownership of the plan and are working towards its goals.

Why choose FCM over other modeling methods? To answer this question, we must consider the issues of model complexity and the reason for the model. Obviously it is important to have a model that is complex enough for the problem to be solved; however data poor situations limit model complexity. Data is costly and often not available, especially in developing countries, where conservation efforts and management are important but not resolved. The multi-step FCM approach described herein is not obtained from empirical data but can be used for modeling perception and therefore social ideas of how systems work. This is essential for conserving an ecosystem where the support of many stakeholders is necessary. It is also useful for extension activities to educate stakeholders, if there are any misperceptions.

The main advantage of the multi-step FCM approach is that it is easy to build and gives qualitative results. It does not require expert knowledge in every field but can be constructed based on simple 
observations by anybody including indigenous or local people. It does not make quantitative predictions but rather shows what will happen to the system in simulations under given conditions of relationships. The model provides a better summary of relationships between variables instead of articulating how that relationship is in detail.

With FCMs the strengths and signs of relationships can be easily changed and simulations run easily and quickly. Thus they are ideal tools for theory development, hypothesis formation, and data evaluation. However, FCMs are not substitutes for statistical techniques; they do not provide real-value parameter estimations or inferential statistical tests.

\subsection{Multi-step FCM approach}

Our multi-step FCM analysis approach includes the following steps:

(1) Drawing of cognitive maps.

(2) Determining if the sample size is adequate.

(3) Coding the cognitive maps into adjacency matrices.

(4) Augmenting individual cognitive maps and then adding them together to form stakeholder social cognitive maps.

(5) Analyzing the structure of individual and social cognitive maps using graph theoretical indices.

(6) Analyzing the differences and similarities in variables among stakeholder groups.

(7) Condensing complex cognitive maps into simpler maps for comparison purposes.

(8) Analyzing the outcomes of cognitive maps using neural network computation.

(9) Simulating different policy options through neural network computation.

This approach is described in detail in Section 2.

\section{Methods}

\subsection{Obtaining cognitive maps}

Cognitive maps can be obtained in four ways: (1) from questionnaires, (2) by extraction from written texts, (3) by drawing them from data that shows causal relationships, (4) through interviews with people who draw them directly. In this article, the first three methods are described only briefly because they have been covered in detail elsewhere.

Roberts (1976, pp. 333-342) told how to derive cognitive maps from questionnaires. He suggests using the opinions of many experts and also "lay" experts who are knowledgeable or concerned about the problem of interest but who are not necessarily from a specific technical discipline. The procedure first involves identifying variables and then selecting the most important ones to include in the map. Different approaches can be used to do these two steps, such as using a preliminary questionnaire or from meeting with experts. Finally the relationships between the variables are defined by giving the expert ordered pairs of variables in a questionnaire format. This allows systematic comparison of all ordered pairs of variables.

Wrightson (1976, pp. 291-332) described extensively the process of coding cognitive maps from text. Shortly, this method is a form of content analysis (Carley, 1990). The coder looks for "cause concept/linkage/effect concept" relationships. These relationships are usually explicitly stated but sometimes they may be implicit. The original language is maintained as much as possible so that the meaning is not distorted later.

Schneider et al. (1998) detailed how to draw cognitive maps from data. In this method, each variable that has numerical measurements (data) available is represented by a numerical vector, where each vector element represents one measurement. The numerical vectors are transferred into fuzzy sets and each vector element is represented by a grade of membership. Then the relationship between the variables is determined by examining the data, whether the relationship is direct or inverse, and also the closeness of the variables are determined. Finally the correlations among variables are determined and assuming these correlations represent causative relationships the cognitive map can be coded.

The technique we have used involves creating cognitive maps through an in-depth interviewing process using the first two steps of textual analysis for drawing cognitive maps as described by Carley and Palmquist (1992). This involves identifying concepts (variables, factors) and the relationships between those concepts. Interviews may be done with individuals or groups of people. First, how to draw a FCM is explained to 
the interviewee(s) using a completely unrelated map, that is, a map from a neutral problem domain (Taber, 1991). Once the interviewee(s) understand the process of constructing a cognitive map, and then they are able to draw their own map of the issue under investigation. Questions typically are open-ended. For example, a question might be stated as "When I mention this ecosystem (state name here) and its surroundings and its inhabitants what are the variables/things that come to your mind? How do these affect each other?" Depending on the purpose of the research, questions might also be directed, such as "What are the variables/things that affect lake eutrophication? How do these variables affect each other?" After the interviewee is asked to name the most important variables, or things that come to mind about a given system, problem, or desired outcome, these variables are listed on a large piece of paper (we have found $50 \mathrm{~cm} \times 70 \mathrm{~cm}$ to be a practical size). After the interviewee(s) has made a list of variables, they are asked to explain the relationships between the variables. The variables are drawn in the center of the paper and the lines, or edges or links, are drawn between the variables to represent these relationships with arrows to indicate their direction. The lines are given a positive or negative sign and a "strength" of strong, medium, or low or as real numbers between -1 and +1 . For one study, every interviewee should use the same scale, either strong, medium or low or a number between -1 and +1 . At any time in the process more variables (and their relationships) can be added to the map. The interview is finished when interviewees feel that they have completed their maps and have nothing more to add. We recommend constructing your own cognitive map of the system before interviewing other people. Then you will be able to introspectively question your own assumptions and understanding of the system. This also allows you to be aware of your own model and not let your ideas about the system influence others when conducting the interviews. Cognitive maps can also be created in a group process where the group together decides on the important variables and on the causal relationships between those variables. This allows for discussion of the variables and the sign and magnitude of the relationships. We prefer individual drawing of cognitive maps, as then power relationships among group members do not play a role.
Accumulation Curve Number of Variables

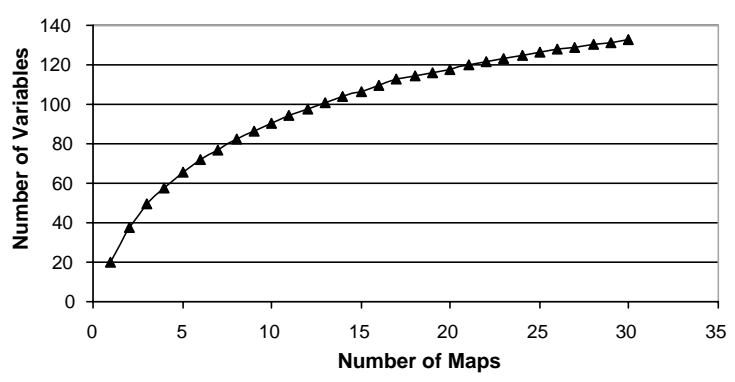

Fig. 1. The total number of variables vs. number of maps.

\subsection{Sample size}

FCMs are created with different people until the population to be represented has been sampled sufficiently. To determine this, we can examine accumulation curves of the total number of variables versus number of interviews as well as the number of new variables added per interview. Average accumulation curves can be made by using Monte Carlo techniques to randomly select many times, i.e. 200, the order of the interviews and determine how the variables accumulate. The accumulation curves based on Monte Carlo techniques can be produced with a spreadsheet or a program such as EstimateS (Colwell, 1997).

Example accumulation curves are shown in Fig. 1 for total number of variables versus number of interviews and in Fig. 2 for the number of new variables added per interview. As the number of interviews increase the total number of variables levels off. The

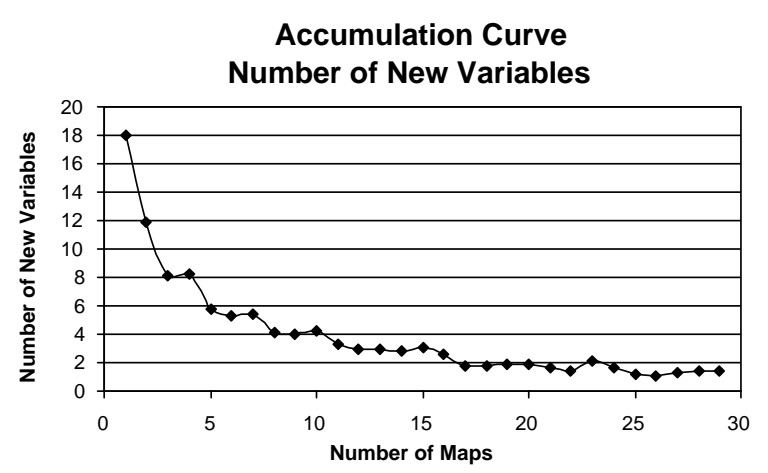

Fig. 2. Number of new variables added per map. 
slow accumulation of variables might be due to a limited vocabulary interviewees have with regards to the subject of inquiry. For example, Carley and Palmquist (1992) report that 29 undergraduates mentioned up to 244 concepts on research writing and 45 students produced 217 concepts on tutor selection. One individual could only consider between 30 and 40 concepts in a session lasting between 20 and 40 min because of combinatorial explosion. In another example, Nakamura et al. (1982) obtained 152 concepts and 265 connections from five documents on traffic problems in Japan. Since people have shared concepts, as the number of concepts increase the rate of increase in total number of concepts will quickly approach zero. However, we might expect that one or two new or unique variables would be mentioned for each new interview (Fig. 2).

\subsection{Coding maps into adjacency matrices}

According to graph theory, cognitive maps can be transformed into adjacency matrices in the form $A(D)=\left[a_{i j}\right]$ (Harary et al., 1965), where the variables $v_{i}$ (e.g. pollution) are listed on the vertical axis and $v_{j}$ (e.g. wetlands) on the horizontal axis to form a square matrix. When a connection exists between two variables the value is coded in the square matrix (between -1 and 1). The cognitive map in Fig. 3 and the adjacency matrix in Fig. 4 show how the connections are coded. For example, -0.2 was entered for $a_{31}$ because there was a causal decrease from $v_{3}$ to $v_{1}$ (e.g. pollution negatively affected wetlands) (Figs. 3 and 4).

\subsection{Social cognitive maps}

Based on Laszlo et al. (1996), individual cognitive maps of interviewees can be augmented, and additively superimposed (Kosko, 1987, 1992a,b) to form a social cognitive map. The first step is to create an aug-

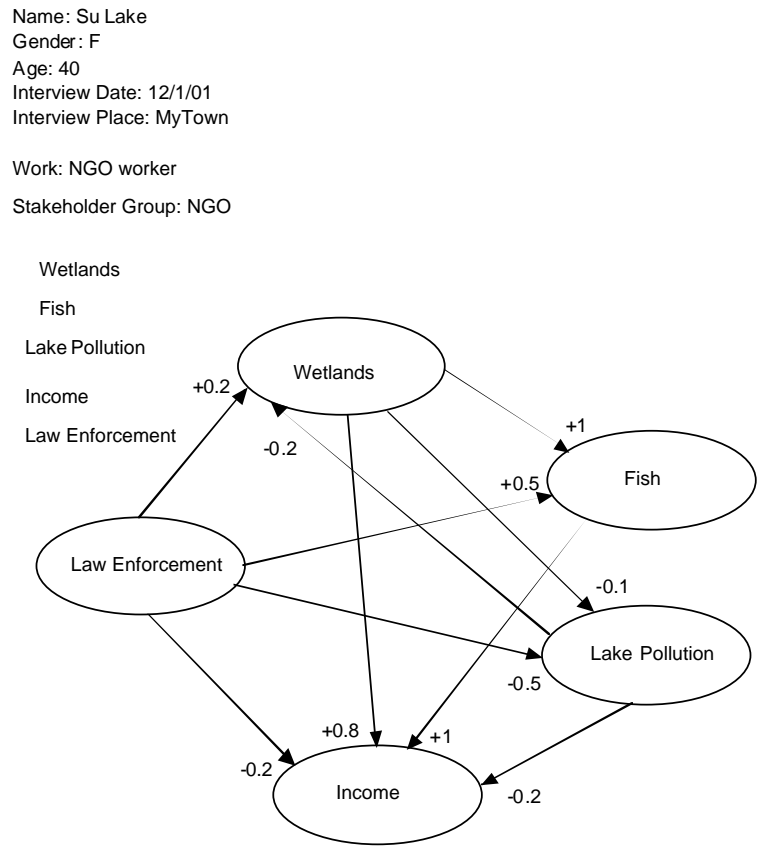

Fig. 3. Example fuzzy cognitive map.

mented matrix that includes all the variables from all the individual cognitive maps. Then each individual cognitive map is coded into an augmented matrix and the individual cognitive maps are added together using matrix addition to create a social cognitive map. If we choose we can normalize each entry in the augmented and summed matrix by the number of cognitive maps included to again put the range of the causal relationships between -1 and +1 (Kosko, 1992b). When adding the maps together, conflicting connections with opposite signs will decrease the causal relationship, while agreement reinforces causal relationships, forming a consensus social cognitive map. Zhang and Chen (1988) point out that the differing directions might be a result of different logical structure and

\begin{tabular}{|l|r|l|r|r|r|}
\hline & $\begin{array}{l}\text { 1.Amount } \\
\text { of wetland }\end{array}$ & $\begin{array}{l}\text { 2. Fish } \\
\text { Population }\end{array}$ & 3. Pollution & 4. Livelihood & 5. Laws \\
\hline 1. Amount of wetland & 0 & 1 & -0.1 & 0.8 & 0 \\
\hline 2. Fish Population & 0 & 0 & 0 & 1 & 0 \\
\hline 3. Pollution & -0.2 & -1 & 0 & -0.2 & 0 \\
\hline 4. Livelihood & 0 & 0 & 0 & 0 & 0 \\
\hline 5. Laws & 0.2 & 0.5 & -0.5 & -0.2 & 0 \\
\hline
\end{tabular}

Fig. 4. Adjacency matrix coded from the fuzzy cognitive map in Fig. 3. 
suggest the use of a negative-positive-neutral calculus to compute compound values for augmented maps. In our work, the addition of augmented matrices has been based on the equivalence properties of fuzzy causal relationships among variables; if arrow directions are switched, signs need to be switched, doing these operations does not change system behavior (Kim and Lee, 1998). When adding together the augmented adjacency matrices, interviewee contributions can be scaled either by multiplying their adjacency matrix by a subjective weight or by assigning weights based on the degree of concurrence (Taber, 1991; Taber and Siegel, 1987). However, Schneider et al. (1998) point out that weights based on concurrence might represent conservative maps at the expense of people thinking differently. In our research so far we have made the assumption that all individual maps are equally valid and a weight of one has been assigned to each individual cognitive map.

The addition of many different cognitive maps might yield a better representation of the system (Eden et al., 1979). Roberts (1973) states that larger groups of experts yield more accurate and reliable information. It was not necessary to have an expert versed in all aspects of the problem, but rather to select many experts from different disciplines to capture the system. Nakamura et al. (1982) found that joining of cognitive maps generated useful information that was not captured by individual maps. Statistically, large numbers of independent and identically distributed (i.i.d.) observations will tend to produce stable edge values (Kosko, 1988), and exponentially diminishing number of new variables. The i.i.d. assumption is reasonable if separate individuals create the cognitive maps and they focus on only one subject, so that the domain focus corresponds to identical distribution (Kosko, 1987, 1988; Taber and Siegel, 1987).

It should be noted that social cognitive maps represent only one point in time. A social cognitive map is not static and evolves as the community itself transforms. Social cognitive maps are "lossy consensus" that dynamically change over time, loosing parts by members leaving a community and others joining in (Carley, 1997). In addition, scientific knowledge can change, as more becomes known about the study system.

\subsection{Graph theory}

Cognitive maps are complex systems because they are made up of a large number of variables that have many interconnections and feedback loops. This structure results in an overall behavior of a system that is different than the sum of units. The analysis of complex cognitive maps is difficult but the matrix algebra tools of graph theory provide a way to analyze their structure. We have found it useful to look at the structure of the maps and make comparisons among stakeholder groups. By examining the structure of maps we can determine how stakeholders view the system, for example whether they perceive a lot of forcing functions affecting the system which are out of their control, or whether they see the system as hierarchical or more democratic.

To analyze a cognitive map, the number of variables $(N)$ and the number of connections $(C)$ in the map can be counted. However, graph theory provides us with many more indices in addition to the number of variables (concepts, statements) and connections (intersections, links, edges).

The density (clustering coefficient) of a fuzzy cognitive map $(D)$ is an index of connectivity, which shows how connected or sparse the maps are

$D=\frac{C}{N(N-1)}$

or alternatively,

$D=\frac{C}{N^{2}}$

To calculate density, the number of connections is divided by the maximum number of connections possible between $N$ variables (Hage and Harary, 1983). If variables can have a causal effect on themselves then maximum number of connections is $N^{2}$. If the density of a map is high then the interviewee sees a large number of causal relationships among the variables. Stakeholders can be compared to see which groups have more relationships among variables. If some groups perceive more relationships, they will have more options available to change things. Thus these groups may be a catalyst for change. In addition, oftentimes experts (government officials, scientists) will belittle the knowledge of other stakeholders. However, by examining the structural indices such as density we have 
usually found that other stakeholder groups perceive as many or more relationships among variables.

The type of variables in a map is important because it shows how the variables act in relation to the other variables. In addition, the number of different types of variables in a cognitive map facilitates an understanding of its structure. The three types of variables are: transmitter variables (forcing functions, givens, tails), receiver variables (utility variables, ends, heads), and ordinary variables (means) (Bougon et al., 1977; Eden et al., 1992; Harary et al., 1965). These variables are defined by their outdegree $\left[\operatorname{od}\left(v_{i}\right)\right]$ and indegree $\left[\operatorname{id}\left(v_{i}\right)\right]$.

Outdegree is the row sum of absolute values of a variable in the adjacency matrix. It shows the cumulative strengths of connections $\left(a_{i j}\right)$ exiting the variable, where $N$ is the total number of variables:

$\operatorname{od}\left(v_{i}\right)=\sum_{k=1}^{N} \bar{a}_{i k}$

Indegree is the column sum of absolute values of a variable. It shows the cumulative strength of variables entering the variable.

$\operatorname{id}\left(v_{i}\right)=\sum_{k=1}^{N} \bar{a}_{k i}$

Transmitter variables have a positive outdegree, $\operatorname{od}\left(v_{i}\right)$, and zero indegree, $\operatorname{id}\left(v_{i}\right)$. Receiver variables have a positive indegree, $\operatorname{id}\left(v_{i}\right)$, and zero outdegree, $\operatorname{od}\left(v_{i}\right)$. Ordinary variables have both a non-zero indegree and outdegree (Bougon et al., 1977). Ordinary variables can be more or less a receiver or transmitter variables, based on the ratio of their indegrees and outdegrees.

The centrality (immediate domain, total degree $\left[\operatorname{td}\left(v_{i}\right)\right]$; Harary et al., 1965) of a variable is the summation of its indegree (in-arrows) and outdegree (out-arrows) (Bougon et al., 1977; Eden et al., 1992; Harary et al., 1965):

$c_{i}=\operatorname{td}\left(v_{i}\right)=\operatorname{od}\left(v_{i}\right)+\mathrm{id}\left(v_{i}\right)$

The contribution of a variable in a cognitive map can be understood by calculating its centrality, which shows how connected the variable is to other variables and what the cumulative strength of these connections are. In fuzzy cognitive maps, but not binary cognitive maps, a variable can be more central although it has fewer connections if the connections carry larger weights (Kosko, 1986).

The total number of receiver variables in a map can be considered an index of its complexity. Many receiver variables indicate that the cognitive map considers many outcomes and implications that are a result of the system (Eden et al., 1992). However, a large number of transmitter variables indicates thinking with top down influences, a "formal hierarchical system" (Simon, 1996, p. 185) and also show "flatness" of a cognitive map where causal arguments are not well elaborated (Eden et al., 1992). Thus we can compare cognitive maps in terms of their complexity by the ratios of number of receiver to transmitter variables $(R / T)$. Complex maps will have larger ratios, because they define more utility outcomes and less controlling forcing functions.

Another structural measure of a cognitive map is the hierarchy index ( $h$ ) (MacDonald, 1983):

$h=\frac{12}{(N-1) N(N+1)} \sum_{i}\left[\frac{\operatorname{od}\left(v_{i}\right)-\left(\sum \operatorname{od}\left(v_{i}\right)\right)}{N}\right]^{2}$

where $N$ is the total number of variables. When $h$ is equal to 1 then the map is fully hierarchical and when $h$ is equal to 0 , the system is fully democratic. Sandell (1996) calls these domination (hierarchical) and adaptation eco-strategies (democratic) pointing out that democratic maps are much more adaptable to local environmental changes because of their high level of integration and dependence. Stakeholders with more democratic maps are more likely to perceive that the system can be changed and thus these stakeholders can be a starting point for achieving management objectives.

Thus the first step in analyzing cognitive maps is to describe and tabulate the number of variables and connections and the graph theory structural indices. The description and the tables can then be used to compare among different interviewees or different groups of stakeholders.

Graph theory indices in discrete or continuous categories can be compared with standard statistical tests (Palmquist et al., 1997). Comparisons by standard statistical tests among maps on the same subject area elicited by the same interviewer are appropriate. Student's $t$-test or ANOVA can be used for comparisons or the non-parametric Mann-Whitney test can 
Table 1

Graph theory indices for the adjacency matrix shown in Fig. 4

\begin{tabular}{|c|c|c|c|c|c|}
\hline & Amount of wetland & Fish population & Pollution & Livelihood & Enforcement of laws \\
\hline Amount of wetland & 0 & 1 & 0.1 & 0.8 & 0 \\
\hline Fish population & 0 & 0 & 0 & 1 & 0 \\
\hline Pollution & 0.2 & 1 & 0 & 0.2 & 0 \\
\hline Livelihood & 0 & 0 & 0 & 0 & 0 \\
\hline Enforcement of laws & 0.2 & 0.5 & 0.5 & 0.2 & 0 \\
\hline Column total, indegree & 0.4 & 2.5 & 0.6 & 2.2 & 0 \\
\hline Row total, outdegree & 1.9 & 1 & 1.4 & 0 & 1.4 \\
\hline Centrality & 2.3 & 3.5 & 2 & 2.2 & 1.4 \\
\hline Transmitter & 0 & 0 & 0 & 0 & 1 \\
\hline Receiver & 0 & 0 & 0 & 1 & 0 \\
\hline Ordinary & 1 & 1 & 1 & 0 & 0 \\
\hline No. of variables & 5 & & & & \\
\hline No. of transmitter variables & 1 & & & & \\
\hline No. of receiver variables & 1 & & & & \\
\hline No. of ordinary variables & 3 & & & & \\
\hline No. of connections & 11 & & & & \\
\hline Connection/variable & 2.2 & & & & \\
\hline Complexity receiver/transmitter & 1 & & & & \\
\hline Density & 0.550 & & & & \\
\hline Hierarchy index, $h$ & 0.203 & & & & \\
\hline
\end{tabular}

be used if samples are rejected to be normal based on Shapiro-Wilk and Kolmogorov-Smirnov Tests of Normality.

An example of the graph theory calculations for the fuzzy cognitive map shown in Fig. 3 (and adjacency matrix of Fig. 4) is given in Table 1. In this map variable 5 , enforcement of laws, is a transmitter variable (Fig. 4). The indegree of enforcement of laws is 0 and the outdegree is 1.5. Enforcement of laws influences the other variables in this map, but none of the other variables have an affect on it. Livelihood, variable 3, on the other hand, is a receiver variable. The outdegree is 0 and the indegree is 2.2. Thus livelihood is influenced by other variables in this map, but it does not affect any of the other variables. The other variables are ordinary variables. The most central variables in this map are fish population, followed by amount of wetland and livelihood. In this example, the map is very small with only five variables. More typical values are discussed in Section 3.3.

\subsection{Comparison of variables in maps}

\subsubsection{Similarity coefficients}

In addition to examining the structure of cognitive maps through graph theory indices we can compare cognitive maps of individuals or stakeholders by making pair-wise comparisons based on which variables the maps include. Similarity coefficients such as S2, S4, or S6 (Gower, 1985 in Systat 5.2 manual, 1992), Phi or Yule $Q$ coefficients can be examined to determine which individuals or groups of stakeholders are most similar. S2 is the proportion of the same variables present in the map, S4 is the proportion of the same variables either present or absent in the maps, and S6 is S4 standardized by all possible patterns of agreement and disagreement. The Phi value indicates the degree of similarity, where 1 is most similar. The Yule $Q$ coefficient is the proportionate reduction in errors in predicting whether or not one group has the variable based on the knowledge that the other group has that variable. The Yule $Q$ value generally corroborates the results from Phi values. The differences in S2, S4, or S6 similarity coefficients or Phi and Yule $Q$ coefficients among groups can be compared with standard statistical tests. In addition, cluster analysis may be performed with these similarity coefficients to determine which individual interviewees or stakeholder groups are most similar or different based on the variables in their maps.

In addition to the coefficients of similarity based on pair-wise comparisons, we have found it useful to 
examine the variables that cognitive maps contain in three different ways.

\subsubsection{Most mentioned variables}

First we can order the variables by how many times they were mentioned in the maps. We would expect that the most important variables would be the ones that were mentioned by the most people. This ordering by the number of times mentioned could be done for all the maps together, to get an idea of what is most important for everyone interviewed. It can also be done for individuals or different groups of stakeholders, to see the differences and similarities in what variables are important or not important for the individuals or different groups.

\subsubsection{Most central variables}

Second we can order the variables by their centrality. When we do this it is also helpful to tabulate the components of how much input they receive, their indegree, and also how much output they give, their outdegree. The centrality of the variable is not only a frequency of expression but also how important that given variable is given the whole structure of the cognitive map. By looking at its indegree and outdegree, we can also see whether the variable is mainly influencing other variables or if other variables influence it or both. This analysis can also be done for all the maps together as well as for individuals or the different stakeholder groups.

\subsubsection{Variable types}

Third, we can separate the variables according to their type, whether they are a transmitter, ordinary, or receiver variable and then order them according to their centrality. The type of variable reveals how people think about the variables. For instance, if someone views a variable as a transmitter variable, it is seen as a forcing function, which cannot be controlled by any other variables. In contrast a receiver variable is seen as not affecting any of the other variables in the system. Again this analysis can be done for individuals, the different stakeholder groups and for all the maps together.

\subsection{Simplifying cognitive maps by condensation}

It is difficult to look at a complex cognitive map with many variables and connections and make sense of how the map operates. Maps with over 20-30 variables start being counterproductive for gaining insights. About 12 variables are typical in an analysis (Buede and Ferrell, 1993). Therefore, the best way to understand complex maps is to simplify them. According to graph theory, condensation is an effective way to simplify complex cognitive maps and understand their structure. Condensation is done by replacing subgraphs (consisting of a group of variables connected with lines) with a single unit (Harary et al., 1965). When replacing groups of variables, the connections of variables within subgraphs with other subgraphs are maintained. Another name for this grouping and replacement is aggregation.

\subsubsection{Quantitative aggregation}

Aggregation can be either quantitative or qualitative. In quantitative aggregation one draws the graphical representation of the cognitive map and visually defines the strong components (re-enforcing cycles) as subgraphs (Harary et al., 1965). This approach is similar to the concept of near-decomposability (Iwasaki and Simon, 1994).

\subsubsection{Qualitative aggregation}

In qualitative aggregation variables can be combined by categories that are represented by a larger encompassing variable. For instance, Nakamura et al. (1982) condensed 152 variables coded from five documents into 16 categories. In our research we have also used qualitative aggregation to subjectively combine variables into categories. After aggregation, the new simplified system can be represented as a cognitive interpretation diagram (CID), where the connections are drawn so that they reflect the weight and sign of the causal relationships, similar to the previously developed neural interpretation diagram (NID) (Özesmi and Özesmi, 1999).

An example of a CID, where 253 variables from the social cognitive map of the stakeholder group local people were qualitatively aggregated into 17 different categories or aggregated variables, is shown in Fig. 5 (Özesmi, 2001b). The thickness of the line is related to the strength of the relationship, with stronger relationships shown by thicker lines. Negative causal relationships are shown as dashed lines, positive causal relationships are shown as solid lines. When drawing the CID, only the strongest connections were shown. 


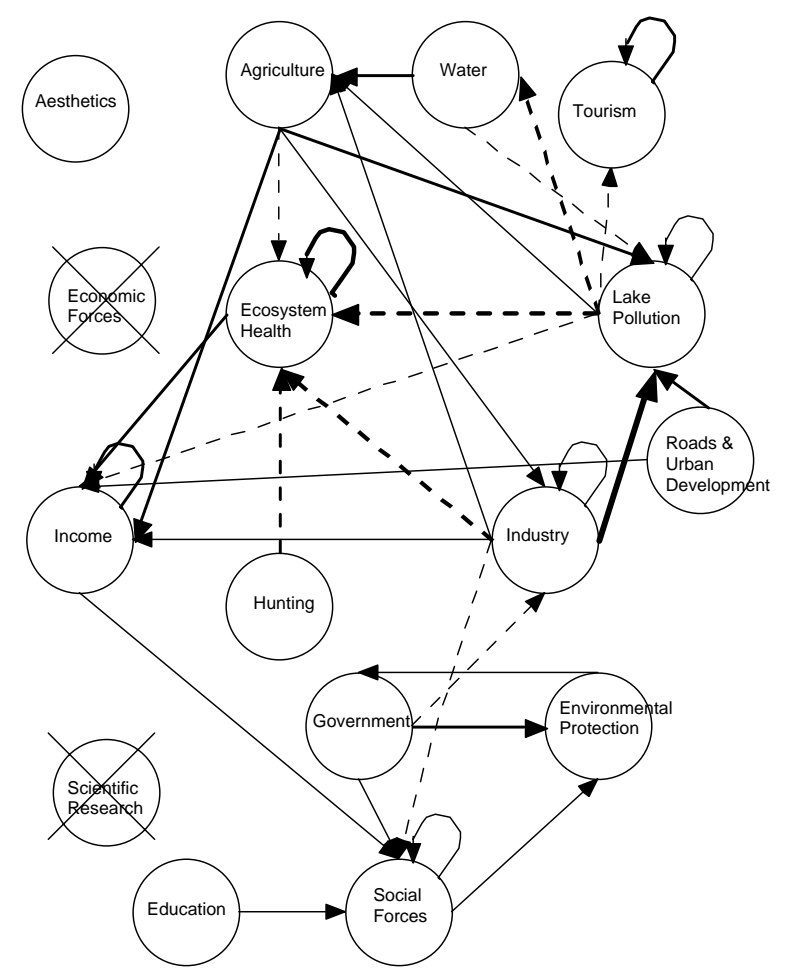

Fig. 5. Example of a cognitive interpretation diagram (CID) of the condensed social map of one stakeholder group (Özesmi, 2001b).

In this case the number of connections was subjectively chosen to be 35 as this allows the relationships to be examined without being too cluttered. If an aggregated variable is not connected to any other aggregated variables, it shows that the connections of that aggregated variable are not among the strongest 35 connections. If an aggregated variable is shown with an "X" over it, it shows that members of this stakeholder group did not mention the variables in this condensed category, although it was present in the maps of other stakeholder groups. By looking at the condensed cognitive map of this stakeholder group, we can easily see what the perceptions of this group are. For example, the strongest relationship in the map is industry increasing lake pollution. Other strong positive relationships are agriculture increasing income but also increasing lake pollution. Ecosystem health also increases income. Strong negative relationships are lake pollution, hunting, and industry decreasing ecosystem health. By creating condensed cognitive maps for different individuals or different stakeholder groups we can easily see in a few figures what aggregated variables and relationships are most important to them and their similarities and differences.

\subsection{Cognitive map inferences}

After the cognitive maps are drawn and the adjacency matrix coded, it is possible run the model to see where the system will go if things continue as they are, that is, to determine the system's steady state. These calculations are made using the auto-associative neural network method (Reimann, 1998). This computational method is not necessarily concerned about the structure, but the outcome, or inference (Kosko, 1987), of the map.

In the neural network computational method, a vector of initial states of variables $\left(I^{n}\right)$ is multiplied with the adjacency matrix A of the cognitive map. The matrix values are of variable strength, which are represented by real numbers. The lines carry the input from one variable (what is called a point, node, or unit) to another activating the unit. The contribution of one connection to the unit is the product of the activity on the line and the value of the connection strength. The total input to the unit is the sum of all the individual products (Fig. 6). Lines can be positive or negative. Positive connections add to the activity total, while negative connections subtract from it. The output of the unit is a function of the total input. Usually a threshold function or a transformation by a bounded monotonic increasing function is applied to the result of the matrix multiplication, $I^{n} \times A$, at each simulation time step (Kosko, 1987, 1992b). Logistic, linear threshold or step functions are commonly used

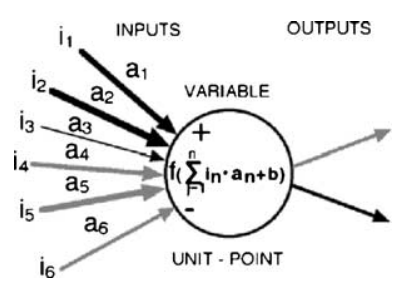

Fig. 6. A simulated unit representing a variable in the cognitive model. Black arrows represent positive signed connections and gray ones negative signed connections. All inputs are multiplied by the weights of connections and then summed. The summation is input into a monotonic increasing function. The result is then output to other connected units. 
activation functions. Typically we have used a logistic function $1 /\left(1+\mathrm{e}^{-1 \times x}\right)$ to transform the results into the interval $[0,1]$. This non-negative transformation allows for a better understanding and representation of activation levels of variables. It also enables a qualitative comparison among the causal output of variables. The resulting transformed vector is then repeatedly multiplied by the adjacency matrix and transformed until the system converges to a fixed point. Typically it converges in less than 30 simulation time steps. All the models we have run have ended in a stable state but theoretically they could have also settled into a limit cycle, or chaotic attractor (Dickerson and Kosko, 1994).

An example of a steady state calculation and a simulated policy option calculation for the FCM from Fig. 3 is shown in Table 2. From the steady state calculation we can get an idea of the ranking of the variables in relationship to each other according to how the system is perceived in the FCM. For example, Table 2 shows that in the steady state, pollution is relatively lower than fish population or livelihood. Thus in this wetland system, pollution is not severely harming the fish population or the livelihood.

\subsection{Policy option simulations}

It is also possible to ask "what-if" questions and make runs to determine what state the system will go to under different conditions or if different policy options are implemented (Kosko, 1987). These calculations can be made on individual cognitive maps, group, or social cognitive maps and the resulting system states compared.

Two characteristics of cognitive maps become apparent when making these runs. The first one is their emergent properties. The sum of the results of individual cognitive maps is not the same as the result from the run of the social cognitive map. The second characteristic of cognitive maps is related and shows the possibility of synergistic interaction among different management or policy options. That is, the effect of implementing two different policy options at the same time is not simply the sum of implementing each policy option separately and adding the results.

In an example of a policy option run, the enforcement of laws is clamped at a high level (1). If the difference between enforcement of laws at a high level and steady state is calculated, according to this FCM having high enforcement of laws will increase the fish population and reduce pollution (Table 3 ). The amount of wetland increases slightly and the amount of livelihood decreases slightly but these variables are affected by the enforcement of laws less than fish population and pollution.

Fig. 7 shows how different policy options would affect important variables in a system according to

Table 2

Calculation of steady state for the FCM shown in Fig. 3

\begin{tabular}{lllccc}
\hline & Amount of wetland & Fish population & Pollution & Livelihood & Enforcement of laws \\
\hline Amount of wetland & 0 & 1 & -0.1 & 0.8 & 0 \\
Fish population & 0 & 0 & 0 & 1 & 0 \\
Pollution & -0.2 & -1 & 0 & -0.2 & 0 \\
Livelihood & 0 & 0 & -0.5 & -0.2 & 0 \\
Enforcement of laws & 0.2 & 0.5 & & 0 & \\
FCM simulation & & & 1 & 1 & 1 \\
$\quad$ Initial state vector & 1 & 1 & 0.47003595 & 0.569546224 & 0.5 \\
& 0.5 & 0.52497919 & 0.48500450 & 0.536483643 & 0.5 \\
& 0.50029964 & 0.51399455 & 0.535800301 & 0.5 \\
& 0.500149955 & 0.51326165 & 0.48500300 & 0.535757901 & 0.5 \\
Steady state & 0.50014997 & 0.51325424 & 0.48500375 & 0.535757526 & 0.5 \\
& 0.500149963 & 0.51325421 & 0.48500375 & 0.5 & 0.5 \\
& 0.500149963 & 0.51325421 & 0.48500375 & 0.535757524 & 0.5 \\
\end{tabular}


Table 3

Run of policy option enforcement of laws for the FCM shown in Fig. 3

\begin{tabular}{|c|c|c|c|c|c|}
\hline & Amount of wetland & Fish population & Pollution & Livelihood & Enforcement of laws \\
\hline \multicolumn{6}{|l|}{ FCM simulation } \\
\hline \multirow[t]{9}{*}{ Initial state vector } & 1 & 1 & 1 & 1 & 1 \\
\hline & 0.5 & 0.524979187 & 0.470035948 & 0.569546224 & 1 \\
\hline & 0.505299442 & 0.526473423 & 0.472527696 & 0.531506799 & 1 \\
\hline & 0.505274527 & 0.526613412 & 0.472501279 & 0.531767523 & 1 \\
\hline & 0.505274792 & 0.526613487 & 0.472501403 & 0.531773764 & 1 \\
\hline & 0.50527479 & 0.526613494 & 0.472501401 & 0.531773777 & 1 \\
\hline & 0.50527479 & 0.526613494 & 0.472501401 & 0.531773778 & 1 \\
\hline & 0.50527479 & 0.526613494 & 0.472501401 & 0.531773778 & 1 \\
\hline & 0.50527479 & 0.526613494 & 0.472501401 & 0.531773778 & 1 \\
\hline \multicolumn{6}{|c|}{ Difference between strong enforcement of laws and steady state } \\
\hline & 0.005124827 & 0.013359289 & -0.012502348 & -0.003983746 & 0.5 \\
\hline
\end{tabular}

the perceptions of the interviewees. The height of the bars in the chart show the relative difference between the values of the variable given the policy option and given the steady state. Different policy options can be compared in a chart format such as this to see which would have the most affect on the variables of interest and to see the relative effects of different policy options. In this example, completely eliminating domestic wastes results in the greatest reduction in lake pollution and the largest increase in lake protection. Sewage treatment has the next largest effect on lake pollution and lake protection.

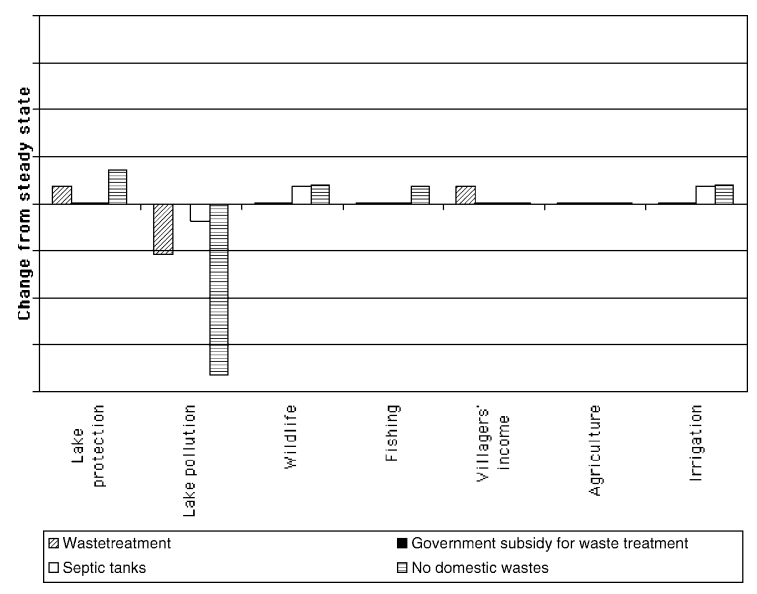

Fig. 7. Chart showing the relative effects of different policy options on lake ecosystem variables.

\section{Discussion}

\subsection{Examples from our research}

Özesmi (1999a,b) used FCM to examine the views of different stakeholders in an environmental conflict. Government and non-governmental organization (NGO) officials wanted to create a national park to protect an important wetland delta ecosystem on the coast of north central Turkey while local people opposed this plan. In this case FCM was useful to obtain the opinions of the different stakeholders. The transparency of this method made it less suspect than questionnaires for local people. Local people had a significantly larger numbers of variables, more complex maps, and mentioned more variables that controlled the ecosystem than did NGO and government officials. Local people also mentioned more variables related to agriculture and animal husbandry, their main sources of livelihood. From the FCM analysis the sources of conflict were made quite clear and lessons learned from the analysis have been applied to other conservation projects.

Özesmi (2001a) used FCM to obtain the wants and desires of people that were to be displaced by a construction of a large hydroelectric dam during and after resettlement. By obtaining their opinions on what would most increase their welfare, the compensation could focus specifically on what displaced people wanted. In addition, through policy option simulations, it was possible to determine which policies 
and combination of policies would increase the welfare of the people the most, according to their own perceptions.

Özesmi and Özesmi $(2001,2003)$ used FCM of different stakeholder groups to facilitate creation of a participatory environmental management plan for an important wetland ecosystem in northwestern Turkey. With the FCM analysis it was possible to determine what the most important goals were for the different stakeholders and to design the management plan accordingly. This enabled support for and participation in the activities of the management plan by the stakeholders.

Yalçın and Seçme (2001) used FCM to obtain the opinions of middle and high-level managers about the problems and opportunities for local industry in Kayseri, Turkey. High-level managers were focusing more on financial variables whereas middle level managers were focusing on operations and quality. Both levels of managers did not mention any variables related to the environment.

Dadaser and Özesmi (2001) and Dadaser (2002) used FCM to compare the perceptions of local people, NGO and government officials concerning a salt lake ecosystem in central Turkey. From the analysis the concerns of local people came out and potential barriers to conservation plans were discovered. Sixty-five different policy option simulations were done based on stakeholders' input.

Dadaser and Özesmi (2002) used FCM to analyze stakeholder perceptions about a wetland of international importance in central Turkey. This research again highlighted the importance of livelihood, including agriculture, animal husbandry, reed cutting and tourism, to people living around wetland ecosystems in Turkey. The study emphasized the need for conservation strategies that not only achieve ecosystem conservation but also support sustainable economic activities and increase local people's welfare.

\subsection{Structure of cognitive maps}

Comparing the number of variables and indices of cognitive maps across different subject areas and interviewers should be done with caution, because cognitive maps are dependent on the length of text or duration of interview and the skill of the interviewer
(Eden et al., 1992). Thus values from the literature from different studies on the number of variables, connections and other graph theoretical indices are shown only to give readers an approximate idea (Tables 4 and 5). However, we found out that if a standard methodology is used the structural indices of the maps from separate studies are in the same range (Tables 6 and 7). In our research, which included the six different studies described previously, the average time for completing a cognitive map varied from 40 to 90 min (Table 6). These individual cognitive maps contained on average $23 \pm 2$ S.D. variables with $37 \pm 7$ S.D. connections. The average number of transmitter variables in the individual cognitive maps were $8 \pm 3$ S.D. and in receiver and ordinary variables $4 \pm 3$ and $11 \pm 3$ S.D., respectively. The number of transmitter variables was almost always higher than the number of receiver variables in both the individual and social cognitive maps. This indicates that the interviewees perceived the systems as having more forcing functions than utility variables. The number of receiver to transmitter variables averaged $0.6 \pm 0.3$ S.D. in the individual cognitive maps. The majority of the variables were always ordinary variables for both the social and individual cognitive maps. The number of connections per variable in the individual maps was on average $1.6 \pm 0.3$ S.D. The average density and hierarchy indices were $0.08 \pm 0.03$ and $0.05 \pm 0.02$ S.D., respectively. The density indicates relatively sparse maps and the hierarchy index indicates that the maps are much more "democratic" than "hierarchical". Generally the graph theory indices showed more variation among the social cognitive maps compared to the average of the individual maps in the various studies.

\subsection{Model validation}

Interviewees may draw cognitive maps that emphasize different parts of a system based on their experiences, which need not imply that some maps are wrong or less representative than others. Formal validation of these cognitive maps is not possible because the maps operate on different understandings of the system. They are qualitative models that do not yield outputs directly measurable in nature. The question of whether some cognitive maps represent reality better than others might not be possible because the reality 
Table 4

Values for the number of variables, number of connections, and graph theory indices from the literature

\begin{tabular}{|c|c|c|c|c|c|c|c|c|c|}
\hline & \multicolumn{9}{|l|}{ Source } \\
\hline & Malone $(1975)^{\mathrm{a}, \mathrm{b}}$ & Hart $(1977)^{\mathrm{c}}$ & $\begin{array}{l}\text { Klein and } \\
\text { Cooper }(1982)^{c}\end{array}$ & $\begin{array}{l}\text { Langfield-Smith } \\
\text { (1992) }\end{array}$ & $\begin{array}{l}\text { Cossette and } \\
\text { Audet }(1992)^{b, c}\end{array}$ & Brown (1992) & Eden et al. (1992) & $\begin{array}{l}\text { Carley and } \\
\text { Palmquist (1992) }\end{array}$ & $\begin{array}{l}\text { Craiger et al. } \\
(1996)^{b}\end{array}$ \\
\hline Subject & $\begin{array}{l}\text { Urban } \\
\text { development }\end{array}$ & $\begin{array}{l}\text { Latin American } \\
\text { politicians }\end{array}$ & $\begin{array}{l}\text { Army battle } \\
\text { simulation }\end{array}$ & $\begin{array}{l}\text { Qualities of fire } \\
\text { protection officer }\end{array}$ & $\begin{array}{l}\text { Small business } \\
\text { environment }\end{array}$ & Business strategy & & & $\begin{array}{l}\text { Job } \\
\text { satisfaction }\end{array}$ \\
\hline No. of maps, $n$ & $\begin{array}{l}8 \text { students } \\
\text { created } 1 \text { map }\end{array}$ & 3 & 14 & 2 & 1 & 116 & & & 1 \\
\hline No. of variables per map, $N$ & 22 & $37,34,37$ & $19 \pm 5$ & 16,19 & 57 & $\begin{array}{l}32 \text { modal average } \\
\text { (range: } 14-59 \text { ) }\end{array}$ & & $30-40$ & 22 \\
\hline No. of transmitter variables & & & & & 13 & & & & 4 \\
\hline No. of receiver variables & & & & & 10 & & & & 2 \\
\hline No. of ordinary variables & & & & & 34 & & & & 16 \\
\hline No. of connections, $C$ & 29 & $43,48,50$ & $27 \pm 9$ & 21,24 & 87 & & & & 47 \\
\hline Connection/variable & 1.32 & & $1.4 \pm 0.2$ & & 1.53 & & Typically $1.15-1.20$ & & 2.14 \\
\hline Reciever/transmitter & & & & & 0.77 & & & & 0.5 \\
\hline Density, $D$ & 0.063 & & $0.089 \pm 0.043$ & & 0.027 & & & & 0.102 \\
\hline Hierarchy index, $h$ & & & & & & & & & 0.0194 \\
\hline Time (min) & 150 & & & & & 75 modal average & & $20-40$ & \\
\hline
\end{tabular}


Table 5

Values from the literature for the total number of variables across all maps, total number of connections, and graph theory indices

\begin{tabular}{llcr}
\hline & Source & & \\
\cline { 2 - 4 } & Carley and Palmquist (1992) & Carley and Palmquist (1992) & Nakamura et al. (1982) ${ }^{\mathrm{a}, \mathrm{b}}$ \\
\hline Subject & Tutor selection & Research writing & Traffic problems in Japan \\
No. of maps, $n$ & 45 & 29 & 5 \\
Total number of variables across & 217 & 244 & 152 \\
$\quad$ all maps & & & 265 \\
Total number of connections, $C$ & & 1.74 \\
Connection/variable & & 0.01 \\
Density, $D$ & & & \\
\hline
\end{tabular}

\footnotetext{
a Map(s) coded from text.

b We calculated the density and connections per variable.
}

with which the model outputs are compared is mediated through yet another understanding. For example, in a study of the Kizilirmak Delta wetland ecosystem in Turkey (Özesmi, 1999a) villagers disputed the level of biodiversity assessed by researchers and said that only commonly breeding birds can be used for evaluating the importance of the delta for bird species. Researchers had assessed use of the delta by both breeding and migrating birds.

However, where two expert opinions are to be compared, how well they fit reality can be compared in a qualitative manner. In addition a qualitative validation can be made in terms of a "reality check" rather than formal validation. For example, if a map predicts a crash in fish populations and fishing people are having record harvests year after year, then obviously something is wrong with the construction of the model. Also see Hobbs et al. (2002), who adjusted their model to ensure that its behavior was qualitatively consistent with empirically established relationships. Therefore some level of validation can be achieved. In these cases, Klein and Cooper (1982) found that the performance of the cognitive map is independent of the number of variables or relationships. So cognitive maps can be representing reality successfully even if they are not highly complex. One might expect that cognitive map performance is bell-shaped from simplicity going to complexity as postulated by Jørgensen (1994) for ecological models. However, the issue has not been researched enough yet and there is space to determine the performance of cognitive maps depending on their density, hierarchy, and complexity.

\subsection{Advantages and disadvantages of cognitive maps}

The main advantages of cognitive maps include: (1) the ability to allow feedback processes (Kosko, 1987), (2) the ability to deal with many variables which may be not well-defined (Kosko, 1986), (3) ability to model relationships between variables that are not known with certainty, but can be described in degrees such as a little or a lot (Kosko, 1986), (4) the ability to model systems where scientific information is limited but expert and/or local knowledge is available, (5) ease and speed with which cognitive maps may be obtained (Kosko, 1992a,b; Taber, 1991) and reach similar results with lower sample sizes as compared to other techniques (Özesmi, 2001a), (6) ease and speed with which many different knowledge sources can be combined (Kosko, 1992a), including expert and local knowledge, (7) ease and speed of modeling the system and the effect of different policy options.

The disadvantages of cognitive maps are: (1) the interviewees' knowledge, ignorance, misconceptions and biases are all encoded in the maps (Kosko, 1992b), unless these presumed ignorance and misconceptions are the subject of study, (2) although what-if's can be modeled in FCMs why's cannot be determined (Kim and Lee, 1998), (3) they do not provide real-value parameter estimates or inferential statistical tests (Craiger et al., 1996), (4) lack of a concept of time (Schneider et al., 1998); that is, they cannot model transient behavior (Hobbs et al., 2002), (5) they cannot deal with co-occurrence of multiple causes such 
Table 6

Number of variables, number of connections, and graph theory indices for individual cognitive maps from our research

\begin{tabular}{|c|c|c|c|c|c|c|c|c|c|c|c|c|}
\hline & \multicolumn{12}{|c|}{ Individual cognitive maps } \\
\hline & \multicolumn{2}{|c|}{$\begin{array}{l}\text { Kizilirmak Delta } \\
\text { (Özesmi, 1999a,b) }\end{array}$} & \multicolumn{2}{|c|}{$\begin{array}{l}\text { Yusufeli } \\
\text { (Özesmi, 2001a) }\end{array}$} & \multicolumn{2}{|c|}{$\begin{array}{l}\text { Uluabat Lake } \\
\text { (Özesmi and Özesmi, 2001) }\end{array}$} & \multicolumn{2}{|c|}{$\begin{array}{l}\text { Kayseri Industry } \\
\text { (Yalçın and Seçme, 2001) }\end{array}$} & \multicolumn{2}{|c|}{$\begin{array}{l}\begin{array}{l}\text { Sultan Marshes } \\
\text { (Dadaser and Özesmi, 2002) }\end{array} \\
\end{array}$} & \multicolumn{2}{|c|}{$\begin{array}{l}\begin{array}{l}\text { Tuzla Lake } \\
\text { (Dadaser and Özesmi, 2001) }\end{array} \\
\end{array}$} \\
\hline & Mean & S.D. & Mean & S.D. & Mean & S.D. & Mean & S.D. & Mean & S.D. & Mean & S.D. \\
\hline No. of maps, $n$ & 31 & & 13 & & 35 & & 30 & & 56 & & 44 & \\
\hline No. of variables, $N$ & 19 & 7 & 24.2 & 5.7 & 24.5 & 9.6 & 21.4 & 6.1 & 24.4 & 4.4 & 24.9 & 8.4 \\
\hline No. of transmitter variables, $T$ & 7 & 4.3 & 9.1 & 3.2 & 7.8 & 4.7 & 5.2 & 3.4 & 7 & 1.5 & 9.4 & 3.8 \\
\hline No. of receiver variables, $R$ & 3 & 2.4 & 1.6 & 1.1 & 2.8 & 2.6 & 3.1 & 2.5 & 8 & 2.6 & 7.8 & 3.1 \\
\hline No. of ordinary variables, $O$ & 8.9 & 3.3 & 13.5 & 6.5 & 13.9 & 6.6 & 13.1 & 4.9 & 9.7 & 3.8 & 7.8 & 5.1 \\
\hline No. of connections, $C$ & 28.3 & 10.6 & 43.6 & 17.6 & 43.7 & 22.1 & 43.5 & 14.8 & 31.3 & 8.4 & 31.2 & 26.6 \\
\hline Connection/variable, $C / N$ & 1.64 & 0.95 & 1.76 & 0.51 & 1.8 & 0.6 & 2.07 & 0.6 & 1.3 & 0.2 & 1.2 & 0.5 \\
\hline Complexity, $R / T$ & 0.522 & 0.492 & 0.228 & 0.252 & 0.435 & 0.466 & 0.6 & 0.7 & 0.989 & 0.476 & 0.923 & 0.497 \\
\hline Density, $D$ & 0.112 & 0.109 & 0.078 & 0.022 & 0.087 & 0.041 & 0.11 & 0.05 & 0.055 & 0.008 & 0.051 & 0.017 \\
\hline Hierarchy index, $h$ & 0.082 & 0.135 & 0.025 & 0.014 & 0.043 & 0.049 & 0.08 & 0.11 & 0.045 & 0.033 & 0.036 & 0.035 \\
\hline Average time (min) & 90 & & 56 & 15 & & & 41 & & 40 & & 43 & \\
\hline Minimum time (min) & 45 & & 35 & & & & 25 & & 20 & & 20 & \\
\hline Maximum time (min) & 240 & & 95 & & & & 90 & & 90 & & 175 & \\
\hline
\end{tabular}


Table 7

Values for the number of variables, number of connections, and graph theory indices for social cognitive maps from our research

\begin{tabular}{|c|c|c|c|c|c|c|}
\hline & \multicolumn{6}{|c|}{ Social cognitive maps } \\
\hline & $\begin{array}{l}\text { Kizilirmak Delta } \\
\text { (Özesmi, 1999a,b) }\end{array}$ & $\begin{array}{l}\text { Yusufeli } \\
\text { (Özesmi, 2001a) }\end{array}$ & $\begin{array}{l}\text { Uluabat Lake } \\
\text { (Özesmi and Özesmi, 2001) }\end{array}$ & $\begin{array}{l}\text { Kayseri Industry } \\
\text { (Yalçın and Seçme, 2001) }\end{array}$ & $\begin{array}{l}\text { Sultan Marshes } \\
\text { (Dadaser and Özesmi, 2002) }\end{array}$ & $\begin{array}{l}\text { Tuzla Lake } \\
\text { (Dadaser and Özesmi, 2001) }\end{array}$ \\
\hline Subject & $\begin{array}{l}\text { Conflict over } \\
\text { protection for a } \\
\text { wetland }\end{array}$ & $\begin{array}{l}\text { Wants and desires of people } \\
\text { affected by resettlement }\end{array}$ & $\begin{array}{l}\text { Participatory management } \\
\text { plan for Uluabat Lake } \\
\text { ecosystem }\end{array}$ & $\begin{array}{l}\text { Problems and opportunities } \\
\text { of small industry }\end{array}$ & $\begin{array}{l}\text { Sultan Marshes wetland } \\
\text { ecosystem }\end{array}$ & $\begin{array}{l}\text { Tuzla Lake wetland } \\
\text { ecosystem }\end{array}$ \\
\hline No. of maps, $n$ & 31 & 13 & 35 & 30 & 56 & 44 \\
\hline No. of variables, $N$ & 136 & 97 & 253 & 135 & 181 & 204 \\
\hline No. of transmitter variables, $T$ & 27 & 24 & 69 & 14 & 31 & 51 \\
\hline No. of receiver variables, $R$ & 9 & 2 & 8 & 9 & 32 & 20 \\
\hline No. of ordinary variables, $O$ & 100 & 71 & 176 & 112 & 118 & 133 \\
\hline No. of connections, $C$ & 616 & 360 & 1173 & 948 & 773 & 864 \\
\hline Connection/variable & 4.616 & 3.711 & 4.636 & 7.02 & 4.27 & 4.24 \\
\hline Complexity, $R / T$ & 0.333 & 0.083 & 0.116 & 0.64 & 1.03 & 0.39 \\
\hline Density, $D$ & 0.033 & 0.038 & 0.018 & 0.05 & 0.024 & 0.021 \\
\hline Hierarchy index, $h$ & 0.026 & 0.0485 & 0.0107 & 0.08 & 0.118 & 0.0242 \\
\hline
\end{tabular}


as expressed by "and" conditions (Schneider et al., 1998), (6) "if, then" statements cannot be coded.

The first disadvantage can be partially overcome by adding many cognitive maps together (see Section 2.3). By combining the maps of many experts or informed local people the accuracy of the map can be improved. The strong law of large numbers ensures that the knowledge estimate improves with the number of experts if the experts are viewed as independent (unique) random knowledge sources with finite variance (bounded uncertainty) and identical distribution (same problem-domain focus) (Dickerson and Kosko, 1994).

The second disadvantage that FCM's do not show "why's" can be partially overcome by examining cognitive interpretation diagrams where it is easier to trace the causal relationships from variable to variable. We can see what causal relationships are most important and how the variables affect other variables.

\section{Conclusions}

In our experience the advantages of using multi-step FCM outweigh its disadvantages. In particular we have found it useful for obtaining the perceptions of different people in different stakeholder groups concerning an ecosystem. This allows for more appropriate conservation strategies and management plans to be made. We found that when FCMs were created with a standard methodology the structural indices of the maps were close to each other even across separate studies. This result suggests that FCMs could be used in a meta analysis, to compare for example people's perceptions of ecological systems in different areas. As a modeling tool, FCMs have not been exploited to their full capacity in ecology. However, cognitive mapping has some important advantages for ecological problem solving and decision-making, especially when many stakeholders are involved. With cognitive mapping complex and abstract variables that cannot easily be measured but are important to decision-making can be modeled. This approach is especially appropriate for data poor situations. The opinions of many different experts and local knowledge can be combined. The effects of different policy options can be simulated quickly and easily as part of the multi-step modeling approach.

\section{References}

Axelrod, R., 1976. Structure of Decision: The Cognitive Maps of Political Elites. Princeton University Press, Princeton, NJ.

Bauer, V., 1975. Simulation, evaluation and conflict analysis in urban planning. In: Baldwin, M.M. (Ed.), Portraits of Complexity, Applications of Systems Methodologies to Societal Problems. Battelle Institute, Columbus, OH, pp. 179-192.

Biggs, N.L., Lloyd, E.K., Wilson, R.J., 1976. Graph Theory: 1736-1936. Clarendon Press, Oxford.

Bougon, M., Weick, K., Binkhorst, D., 1977. Cognition in organizations: an analysis of the Utrecht Jazz Orchestra. Admin. Sci. Quart. 22, 606-639.

Brown, S.M., 1992. Cognitive mapping and repertory grids for qualitative survey research: some comparative observations. J. Manage. Stud. 29, 287-307.

Buede, D.M., Ferrell, D.O., 1993. Convergence in problem solving: a prelude to quantitative analysis. IEEE Trans. Syst., Man, Cybernet. 23, 746-765.

Carley, K., 1990. Content analysis. In: Asher, R.E. (Ed.), The Encyclopedia of Language and Linguistics, vol. 2. Pergamon, Edinburgh, pp. 725-730.

Carley, K., 1997. Extracting team mental models through textual analysis. J. Org. Behav. 18, 533-558.

Carley, K., Palmquist, M., 1992. Extracting, representing, and analyzing mental models. Social Forces 70, 601-636.

Colwell, R.K., 1997. Estimate S: Statistical estimation of species richness and shared species from samples. Version 5. User's Guide and application published at: http://www.viceroy.eeb. uconn.edu/estimates.

Cossette, P., Audet, M., 1992. Mapping of an idiosyncratic schema. J. Manage. Stud. 29, 325-347.

Craiger, J.P., Weiss, R.J., Goodman, D.F., Butler, A.A., 1996. Simulating organizational behavior with fuzzy cognitive maps. Int. J. Comput. Intel. Org. 1, 120-133.

Dadaser, F., Özesmi, U., 2001. Tuzla golu ekosistemi icin katilimci yonetim plani yontemi: bulanik biliseel haritalama yaklasimi (Participatory management plan for Tuzla Lake ecosystem: a fuzzy cognitive mapping approach). In: Proceedings of the IV National Environmental Engineering Congress, Mersin, Turkey, 7-10 November 2001, pp. 25-34.

Dadaser, F., Özesmi, U., 2002. Stakeholder analysis for Sultan Marshes ecosystem: a fuzzy cognitive approach for conservation of ecosystems. In: EPMR2002, Environmental Problems of the Mediterranean Region, Nicosia, North Cyprus, 12-15 April 2002.

Dadaser, F., 2002. Katilimci Yonetim Yaklasimiyla Tuzla Golu Ekosistem icin Cevre Yonetim Plani (An environmental management plan for Tuzla Lake ecosystem with a participatory management approach). M.S. thesis. Erciyes University, Kayseri, Turkey.

Dickerson, J.A., Kosko, B., 1994. Virtual worlds as fuzzy cognitive maps. Presence 3, 173-189.

Dreyfus-Leon, M., Kleiber, P., 2001. A spatial individual behaviour-based model approach of the yellowfin tuna fishery in the eastern Pacific Ocean. Ecol. Model. 146, 47-56.

Eden, C., Ackerman, F., Cropper, S., 1992. The analysis of cause maps. J. Manage. Stud. 29, 309-323. 
Eden, C., Jones, S., Sims, D., 1979. Thinking in Organizations. The Macmillan Press, London.

Gower, J.C., 1985. Measures of similarity, dissimilarity, and distance. In: Kotz, S., Johnson, N.L., Encyclopedia of statistical sciences,vol. 5. John Wiley \& Sons, New York.

Güneralp, B., Barlas, Y., 2003. Dynamic modelling of a shallow freshwater lake for ecological and economic sustainability. Ecol. Model. 167, 115-138.

Hage, P., Harary, F., 1983. Structural Models in Anthropology. Oxford University Press, New York.

Håkanson, L., Boulion, V.V., 2003. A general dynamic model to predict biomass and production of phytoplankton in lakes. Ecol. Model. 165, 285-301.

Harary, F., Norman, R.Z., Cartwright, D., 1965. Structural Models: An Introduction to the Theory of Directed Graphs. John Wiley \& Sons, New York.

Hart, J.A., 1977. Cognitive maps of three Latin American policy makers. World Politics 30, 115-140.

Hjorts $\emptyset$, C.N., 2004. Enhancing public participation in natural resource management using Soft OR-an application of strategic option development and analysis in tactical forest planning. Eur. J. Operation. Res. 152, 667-683.

Hobbs, B.F., Ludsin, S.A., Knight, R.L., Ryan, P.A., Biberhofer, J., Ciborowski, J.J.H., 2002. Fuzzy cognitive mapping as a tool to define management objectives for complex ecosystems. Ecol. Appl. 12, 1548-1565.

Hong, T., Han, I., 2002. Knowledge-based data mining of news information on the Internet using cognitive maps and neural networks. Expert Syst. Appl. 23, 1-8.

Iriondo, J.M., Albert, M.J., Escudero, A., 2003. Structural equation modelling: an alternative for assessing causal relationships in threatened plant populations. Biol. Conserv. 113, 367-377.

Iwasaki, Y., Simon, H.A., 1994. Causality and model abstraction. Artif. Intell. 67, 143-194.

Jöreskog, K.G., 1977. Structural equation models in the social sciences. Specification, estimation and testing. In: Krishnaiah, P. (Ed.), Applications of Statistics. North-Holland Publishing, Amsterdam, pp. 265-287.

Jørgensen, S.E., 1994. Fundamentals of Ecological Modelling. Elsevier, New York, 628 pp.

Kim, H.S., Lee, K.C., 1998. Fuzzy implications of fuzzy cognitive map with emphasis on fuzzy causal relationships and fuzzy partially causal relationship. Fuzzy Sets Syst. 97, 303-313.

Klein, J.H., Cooper, D.F., 1982. Cognitive maps of decision-makers in a complex game. J. Operation. Res. Soc. 33, 63-71.

Kosko, B., 1986. Fuzzy cognitive maps. Int. J. Man-Machine Stud. 1, 65-75.

Kosko, B., 1987. Adaptive inference in fuzzy knowledge networks. In: Proceedings of the First IEEE International Conference on Neural Networks (ICNN-86), San Diego, CA, pp. 261-268.

Kosko, B., 1988. Hidden patterns in combined and adaptive knowledge networks. In: Proceedings of the First IEEE International Conference on Neural Networks (ICNN-86), vol. 2, pp. 377-393.

Kosko, B., 1992a. Fuzzy associative memory systems. In: Kandel, A. (Ed.), Fuzzy Expert Systems. CRC Press, Boca Raton, pp. $135-162$.
Kosko, B., 1992b. Neural Networks and Fuzzy Systems: A Dynamical Systems Approach to Machine Intelligence. Prentice-Hall, Englewood Cliffs, NJ.

Langfield-Smith, K., 1992. Exploring the need for a shared cognitive map. J. Manage. Stud. 29, 349-367.

Laszlo, E., Artigiani, R., Combs, A., Csanyi, V., 1996. Changing visions, human cognitive maps: Past, Present, and Future. Praeger, Westport, Connecticut.

Lee, K.C., Kim, J.S., Chung, N.H., Kwon, S.J., 2002. Fuzzy cognitive map approach to web-mining inference amplification. Expert Syst. Appl. 22, 197-211.

Luria, P., Aspinall, P.A., 2003. Evaluating a multi-criteria model for hazard assessment in urban design. The Porto Marghera case study. Environ. Impact Assess. Rev. 23, 625-653.

MacDonald, N., 1983. Trees and Networks in Biological Models. John Wiley and Sons, New York.

Malone, D.W., 1975. An introduction to the application of interpretive structural modeling. In: Baldwin, M.M. (Ed.), Portraits of Complexity: Applications of Systems Methodologies to Societal Problems, Battelle Institute, Columbus, OH, pp. 119-126.

Mason, R.O., Mitroff, I.I., 1981. Challenging strategic planning assumptions: Theory, cases and techniques. Wiley, New York.

Mendoza, G.A., Prabhu, R., 2003. Qualitative multi-criteria approaches to assessing indicators of sustainable forest resource management. For. Ecol. Manage. 174, 329-343.

Montazemi, A.R., Conrath, D.W., 1986. The use of cognitive mapping for information requirements analysis. MIS Quart. 10, 45-55.

Nakamura, K., Iwai, S., Sawaragi, T., 1982. Decision support using causation knowledge base. IEEE Trans. Syst., Man, Cybernet. SMC 12, 765-777.

Özesmi, U., 1999a. Conservation strategies for sustainable resource use in the Kizilirmak Delta in Turkey. Ph.D. dissertation, University of Minnesota, St. Paul, 230 pp.

Özesmi, U., 1999b. Modeling ecosystems from local perspectives: fuzzy cognitive maps of the Kizilirmak Delta wetlands in Turkey. In: Proceedings of 1999 World Conference on Natural Resource Modelling, Halifax, NS, Canada, 23-25 June 1999.

Özesmi, S.L., Özesmi, U., 1999. An artificial neural network approach to spatial habitat modelling with interspecific interaction. Ecol. Model. 116, 15-31.

Özesmi, U., 2001a. Bilissel (Kognitif) Haritalamaya Gore Halkin Talepleri (The wants and desires of the local population based on cognitive mapping). In: Celil, A. (Ed.), Yusufeli Baraji Yeniden Yerlesim Plani (Yusufeli Damlake Resettlement Plan), Devlet Su Isleri (DSI) (State Hydraulic Works). Sahara Muhendislik, Ankara, pp. 154-169

Özesmi, U., 2001b. Uluabat Golu'nde Sulakalan-Insan Iliskileri ve Ilgi Sahibi Analizi (Uluabat Lake People-Wetland Relations and Stakeholder Group Analysis). DHKD Yayini, Ankara, $90 \mathrm{pp}$.

Özesmi, U., Özesmi, S., 2001. A participatory approach to ecosystem conservation: Uluabat Lake environmental management plan using fuzzy cognitive maps and stakeholder analysis. In: Proceedings of the IV National Environmental 
Engineering Congress, Mersin, Turkey, 7-10 November 2001, pp. 16-24.

Özesmi, U., Özesmi, S., 2003. A participatory approach to ecosystem conservation: fuzzy cognitive maps and stakeholder group analysis in Uluabat Lake, Turkey. Environ. Manage. 31 (4), 518-531.

Palmquist, M.E., Carley, K.M., Dale, T.A., 1997. Application of computer-aided text analysis: Analyzing Literary and Nonliterary Texts. In: Roberts, C.W. (Ed.), Text Analysis for The Social Sciences: Methods for Drawing Statistical Interferenes from Texts and Transcripts. Lawrence Erlbaum Associates, Publishers, Mahwah, NJ, pp. 171-189.

Puccia, C.J., 1983. Qualitative models for east coast benthos. In: Lauenroth, W.K., Skogerboe, G.V., Flug, M. (Eds.), Analysis of Ecological Systems: State-of-the-Art in Ecological Modelling Elsevier, Amsterdam, pp. 719-724.

Radomski, P.J., Goeman, T.J., 1996. Decision making and modeling in freshwater sport-fisheries management. Fisheries 21, 14-21.

Rappaport, R.A., 1979. Ecology, Meaning, and Religion. North Atlantic Books, Richmond, CA.

Reimann, S., 1998. On the design of artificial auto-associative neural networks. Neural Networks 11, 611-621.

Roberts, F.S., 1973. Building and analyzing an energy demand signed digraph. Environ. Plann. 5, 199-221.

Roberts, F.S., 1976. The questionnaire method. In: Axelrod, R. (Ed.), Structure of Decision: The Cognitive Maps of Political Elites. Princeton University Press, Princeton, New Jersey, pp. 333-342.

Sandell, K., 1996. Sustainability in theory and practice: a conceptual framework of eco-strategies and a case study of low-resource agriculture in the dry zone of Sri lanka. In: Hjort-af-Ornãs, A. (Ed.), Approaching Nature from Local Communities: Security Percieved and Achieved. Linköping University, Linköping, Sweden, pp. 163-197.

Schneider, M., Shnaider, E., Kandel, A., Chew, G., 1998. Automatic construction of FCMs. Fuzzy Sets Syst. 93, 161172.
Shipley, B., 2000. Cause and Correlation in Biology: A User's Guide to Path Analysis, Structural Equations and Causal Inference. Cambridge University Press, Cambridge.

Simon, H.A., 1996. The Science of the Artificial. The MIT Press, Cambridge, MA.

Skov, F., Svenning, J.-C., 2003. Predicting plant species richness in a managed forest. For. Ecol. Manage. 6200, 1-11.

Stave, K.A., 2003. A system dynamics model to facilitate public understanding of water management options in Las Vegas, Nevada. J. Environ. Manage. 67, 303-313.

Styblinski, M.A., Meyer, B.D., 1988. Fuzzy cognitive maps, signal flow graphs, and qualitative circuit analysis. In: Proceedings of the 2nd IEEE International Conference on Neural Networks (ICNN-87), San Diego, CA, pp. 549-556.

Taber, W.R., 1991. Knowledge processing with fuzzy cognitive maps. Expert Syst. Appl. 2, 83-87.

Taber, W.R., Siegel, M.A., 1987. Estimation of expert weights using fuzzy cognitive maps. In: Proceedings of the First IEEE International Conference on Neural Networks (ICNN-86), pp. 319-325.

Tolman, E.C., 1948. Cognitive maps in rats and men. Psychol. Rev. 55, 189-208.

Wrightson, M.T., 1976. The documentary coding method. In: Axelrod, R. (Ed.), Structure of Decision: The Cognitive Maps of Political Elites. Princeton University Press, Princeton, NJ, pp. 291-332.

Yalçın, N., Seçme, G., 2001. Bulanik Bilissel Haritama Teknigi Ile Kayseri Sanayiinin Problemlerinin Tespit Edilmesi ve Gelisme Imkanlarinin Gosterilmesi. (Fuzzy cognitive mapping technique to examine the problems and development opportunities for Kayseri Industry). Graduation thesis, Erciyes University Industrial Engineering Department.

Yamada, K., Elith, J., McCarthy, M., Zerger, A., 2003. Eliciting and integrating expert knowledge for wildlife habitat modelling. Ecol. Model. 165, 251-264.

Zhang, W., Chen, S., 1988. A logical architecture for cognitive maps. In: Proceedings of IEEE International Conference on Neural Networks, San Diego, CA, pp. 231-238. 